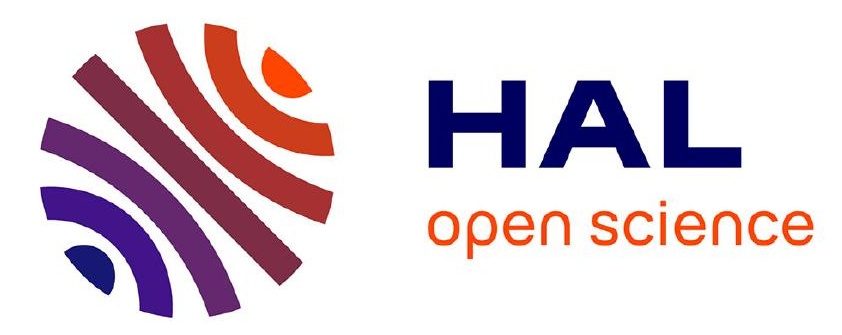

\title{
Increased responsiveness to punishment of cocaine self-administration after experience with high punishment.
}

\author{
Audrey Durand, Paul Girardeau, Luana Freese, Serge H. Ahmed
}

\section{To cite this version:}

Audrey Durand, Paul Girardeau, Luana Freese, Serge H. Ahmed. Increased responsiveness to punishment of cocaine self-administration after experience with high punishment.. Neuropsychopharmacology: official publication of the American College of Neuropsychopharmacology., 2021, 10.1038/s41386-021-01159-3 . hal-03368497

\section{HAL Id: hal-03368497 \\ https://hal.science/hal-03368497}

Submitted on 6 Oct 2021

HAL is a multi-disciplinary open access archive for the deposit and dissemination of scientific research documents, whether they are published or not. The documents may come from teaching and research institutions in France or abroad, or from public or private research centers.
L'archive ouverte pluridisciplinaire HAL, est destinée au dépôt et à la diffusion de documents scientifiques de niveau recherche, publiés ou non, émanant des établissements d'enseignement et de recherche français ou étrangers, des laboratoires publics ou privés. 
Increased responsiveness of cocaine use to punishment with experience

Audrey Durand ${ }^{1}$, Paul Girardeau ${ }^{2}$, Luana Freese ${ }^{3}$, Serge H. Ahmed ${ }^{4,5}$

${ }^{1}$ Imetronic ${ }^{\circledR}, 17$ rue du Bach, 33380 Marcheprime, France ; ${ }^{2}$ Univ. Bordeaux, UFR des Sciences Odontologiques, F-33000 Bordeaux, France ; ${ }^{3}$ Laboratory of Neuropsychopharmacology, Federal University of Health Sciences of Porto Alegre (UFCSPA), Porto Alegre, Rio Grande do Sul, Brazil ; ${ }^{4}$ Univ. Bordeaux, CNRS, IMN, UMR 5293, F-33000 Bordeaux, France ; ${ }^{5}$ CNRS, Univ. Bordeaux, IMN, UMR 5293, F-33000 Bordeaux, France.

\section{Correspondence to:}

Serge H. Ahmed, Ph.D.

Université de Bordeaux

Institut des Maladies Neurodégénératives, UMR CNRS 5293

146 rue Léo Saignât, 33076 Bordeaux, France

E-mail: serge.ahmed@u-bordeaux.fr

Phone: +33557571566

Fax: +33 556900278

Running title: Change in punishment responsiveness 
Change in punishment responsiveness

\section{ABSTRACT}

One behavioral feature of drug addiction is continued drug use despite awareness that this causes negative consequences. Attempts to model this feature in animals typically involve punishing drug self-administration with electrical footshock to identify individuals whose drug use is differently suppressed by punishment. Here we sought to further study individual responsiveness of drug use to punishment in rats self-administering intravenous cocaine. Rats were first trained during several weeks to self-administer cocaine under a fixed-ratio 3 schedule of reinforcement. Then, their self-administration behavior was punished with increasing intensity of footshock (i.e., from $0.1 \mathrm{~mA}$ to $0.9 \mathrm{~mA}$, every $30 \mathrm{~min}$ ). With increasing intensity of punishment, rats first continued to self-administer cocaine before eventually stopping near completely. When retested, however, drug use became more responsive to punishment and was suppressed by a low and initially ineffective footshock intensity (i.e., 0.1 mA). This increase in responsiveness to punishment was seen in all individuals tested, albeit with varying degrees, and was acquired after one single experience with an intensity of punishment that near completely suppressed drug self-administration. Mere passive, noncontingent exposure to the same intensity, however, had no such effect. Once acquired, increased responsiveness to punishment persisted during at least one month when rats were tested every week, but not every day. Finally, increased responsiveness to punishment was not observed after exposure to a non-painful form of punishment (i.e., histamine). Overall, this study reveals that initial responsiveness of drug use to punishment can change rapidly and persistently with experience. We discuss several possible mechanisms that may account for this change in punishment responsiveness and also draw some of the implications and future perspectives for research on animal models of compulsion-like behavior. 


\section{Introduction}

One behavioral feature of drug addiction is continued drug use despite awareness that this causes negative consequences [1-3]. Though becoming aware of a causal relationship between drug use and negative consequences can be difficult, when such awareness eventually emerges it often motivates affected individuals to try quitting drug use, even if these attempts often fail, at least initially, and end up in relapse $[2,4,5]$. It is precisely when individuals attempt to quit drug use to avoid the associated negative consequences, but with no success, that a compulsion-like state is typically inferred $[1,6,7]$. Thus, individual drug users can be considered to have developed addiction when they meet the following three conditions: i) drug use causes negative consequences, ii) drug users become aware of this fact and iii) they have attempted to quit several times and have repeatedly failed - at least initially [1]. The latter clause is added because after several unsuccessful attempts, many drug users eventually succeed to quit drugs [8].

Despite some initial observations [9-12], it is only recently that the role of negative consequences in defining addiction-like behavior in animal models has come under intense scrutiny [13-15]. Interestingly, since drug self-administration is studied under relatively safe laboratory conditions, it has little direct or inherent negative consequences which may contribute to explain why animals do not typically attempt voluntarily to abstain from drug use $[16,17]$. In other words, in a standard drug self-administration setting, condition i) is rarely met. Negative consequences have to be added from outside to drug self-administration. This often involves punishing drug self-administration with a brief electrical footshock $[9,18-20]$. For instance, in a typical punishment experiment, after rats have learned an operant response (e.g., pressing a lever) to self-administer an intravenous drug, this response is 
punished by an immediate footshock while it continues to be also rewarded by the drug, though not always. When the intensity of footshock punishment is fixed (i.e., typically around $0.4 \mathrm{~mA}$ ), one can observe that some animals stop using the drug while others continue using the drug despite footshock punishment $[18,20,21]$. Though we do not know whether and to what extent the latter individual animals can meet conditions ii) and iii) above $[22,23]$, lack of responsiveness of drug use to punishment has generally been interpreted as evidence for a compulsion-like state and its associated neuronal substrates have so far been interpreted uniquely in this light $[20,21,24,25]$.

Though there is clear evidence for individual variation in responsiveness of drug use to footshock punishment, this variation is not all-or-none. Parametric studies that have tested a broad range of footshock intensities present a more nuanced picture [26-38]. Below some low intensities, all individuals continue using despite receiving footshock and, inversely, above some higher intensities, all individuals stop using the drug. As expected, individual variation manifests between these two extremes, with some individuals stopping drug use at higher footshock intensities than other individuals. This simple observation is important because it shows that what differs between individuals is not their ability to stop drug use per se, since all individuals eventually do so, but the punishment intensity that causes them to stop drug use. This observation may beg the question of whether and to what extent a low initial responsiveness of drug use to footshock punishment is a better model of compulsionlike behavior than a higher responsiveness. However, before addressing this question, it is important to further characterize this relative responsiveness to punishment.

In the present study, we tested cocaine self-administering rats with a broad, within-session range of footshock intensities (i.e., 0.1-0.9 mA) to measure the intensity that suppresses by 
$50 \%$ the baseline rate of drug self-administration. We used this measure as a quantitative index of responsiveness of drug use to footshock punishment. After a first assessment of such responsiveness, rats were allowed to recover their pre-punishment levels of drug selfadministration before being retested during a second, identical assessment. Our main finding shows that responsiveness of drug use to footshock punishment changed between these two assessments in all rats tested. Specifically, during the second assessment, drug use became more responsive to punishment than during the first assessment and was near completely suppressed by a low and initially ineffective footshock intensity. We thus conducted a series of original behavioral experiments to try to characterize this acquired responsiveness of drug use to footshock punishment. Overall, our findings show that this increased responsiveness largely results from an individual's prior experience with an intensity of punishment that near completely suppressed drug self-administration. 


\section{Methods}

Subjects

A total of 60 adult male Wistar Han rats (225-250g at the beginning of experiments; Charles

River, Lyon, France) were used in this series of experiments. Rats were housed in groups of 2 or 3 and were maintained in a light- (reverse light-dark cycle), humidity- (60 $\pm 20 \%)$ and temperature-controlled vivarium $\left(21 \pm 2^{\circ} \mathrm{C}\right)$. All behavioral testing occurred during the dark phase of the light-dark cycle. Food and water were freely available in the home cages throughout the duration of the experiment. Home cages were enriched with a nylon gnawing bone and a cardboard tunnel (Plexx BV, The Netherlands). 22 rats did not complete the behavioral experiments which lasted several months, thereby leaving a total of 38 rats for final analysis. Rats did not complete the experiments due to a variety of factors (e.g., failure to acquire cocaine self-administration; infection; catheter failure).

\section{Ethical statement}

All experiments were carried out in accordance with institutional and international standards of care and use of laboratory animals [UK Animals (Scientific Procedures) Act, 1986; and associated guidelines; the European Communities Council Directive (2010/63/UE, $22^{\text {th }}$ of September 2010) and the French Directives concerning the use of laboratory animals (Decree $2013-118,1^{\text {st }}$ of February 2013)]. The animal facility has been approved by the Committee of the Veterinary Services Gironde, agreement number A33-063-922. 


\section{Apparatus}

Six identical operant chambers $(30 \times 40 \times 36 \mathrm{~cm})$ were used for all behavioral testing and training (Imetronic, Pessac, France). They were located away from the colony room in a separate dimly lit room. They were individually enclosed in sound-attenuating wooden cubicles equipped with a white noise speaker $(45 \pm 6 \mathrm{~dB})$ for sound attenuation and an exhaust fan for ventilation. Each chamber was equipped with two retractable metal levers on opposite panels of the chamber, and a corresponding white light diode positioned above each lever. One syringe pump delivered drug solution through Tygon tubing (Cole Parmer, Vernon Hills, IL, USA) connected via a single channel liquid swivel (Lomir Biomedical Inc., Quebec, Canada) to a cannula connector (Plastics One, Roanoke, VA, USA) on the back of the animal. This system of drug self-administration was suspended at the center of the chamber. Finally, the grid floor of each chamber was connected to a generator that delivered scrambled electric footshock. The onset, duration and intensity of each footshock were programmed by the experimenter (see below).

\section{Surgery}

Three days after their arrival in the laboratory, rats were anesthetized with Xylazine (15 mg/kg, intraperitoneal (i.p.), Merial, Lyon, France) and Ketamine (110 mg/kg, i.p., Bayer Pharma, Lyon, France) and were surgically prepared with an indwelling silastic catheter (0.012 inch inner diameter, 0.025 inch outer diameter, Dow Corning Corporation, Michigan, USA) in the right jugular vein. The catheter was secured to the vein with surgical silk sutures and passed subcutaneously to the top of the back about $2 \mathrm{~cm}$ below the scapulae where it exited into a connector (modified 22 gauge cannula). After surgery, animals were flushed daily with $0.2 \mathrm{ml}$ of a sterile ampicillin solution $(0.1 \mathrm{~g} / \mathrm{ml}$, Panpharma, Fougères, France) 
containing heparin $(300 \mathrm{lU} / \mathrm{ml})$ to maintain patency. When a leakage in the catheter was suspected, its patency was checked by an intravenous administration of Etomidate (0.75-1 $\mathrm{mg} / \mathrm{kg}$, Braun Medical, Boulogne-Billancourt, France), a short-acting non-barbiturate anesthetic. Behavioral procedures began 7-10 days after surgery.

Drugs

Cocaine hydrochloride (Coopération Pharmaceutique Française, Melun, France) was dissolved in $0.9 \% \mathrm{NaCl}$, filtered through a syringe filter $(0.22 \mu \mathrm{m})$ and stored at room temperature $\left(21 \pm 2{ }^{\circ} \mathrm{C}\right)$. Drug doses are expressed as the weight of the salt.

Data analysis

All data were subjected to relevant repeated measures ANOVAs, followed by Tukey post hoc tests where relevant. Statistical analyses were run using Statistica, version 7.1 (Statsoft Inc., Maisons-Alfort, France). In all experiments, the first 30-min interval of each session was systematically ignored in within-session analysis of behavior because it includes the initial drug loading phase. During drug loading, cocaine self-administration can indeed be much higher than during the rest of the session [39-41]. In experiment 1, the current intensity that suppresses by $50 \%$ (IS50\%) the rate of cocaine self-administration was assessed by fitting each individual intensity-effect curve with a two-parameter sigmoid function (SigmaPlot 8.02, SPSS Inc., Chicago, IL). 
Change in punishment responsiveness

General behavioral procedures

Cocaine self-administration training

In all experiments, animals were first habituated during 23 -h daily sessions to the operant chamber and the tethering system. During habituation, no lever was presented, and rats were allowed to move freely to explore the chamber. After habituation, rats were progressively trained to press a lever to self-administer cocaine intravenously $(0.25 \mathrm{mg}$ per injection) under a fixed-ratio (FR) 3 schedule of reinforcement during 4-5 weeks. All selfadministration sessions began with extension of the operant lever and ended with its retraction after $2.5-4 \mathrm{~h}$, depending of the experiment (see below). No inactive lever was used in the present study. Intravenous delivery of cocaine began immediately after completion of the operant response requirement and lasted about $4 \mathrm{~s}$. It was accompanied by illumination of the light cue above the lever for $20 \mathrm{~s}$. Responses during the light cue were recorded but had no programmed consequence. All self-administration sessions were run 5 days a week.

Footshock punishment of cocaine self-administration

In all experiments, sessions of footshock punishment were subdivided into 2 main periods: a first period of cocaine self-administration without punishment that lasted $1 \mathrm{~h}$ followed by a second period where cocaine self-administration was punished (see Figure 1). The first period served as a control to measure the effects of footshock punishment on cocaine selfadministration during the second period. During the latter period, footshock punishment was administered immediately after completion of each FR3 requirement and was thus concomitant with onset of i.v. cocaine delivery. The duration of was always $0.5 \mathrm{~s}$ but its 
intensity as well as the schedule of its administration varied as a function of each specific experiment (see below).

Specific behavioral experiments

Experiment 1: Measurement of responsiveness to footshock punishment

The goal of this initial experiment was to measure cocaine self-administration's responsiveness to increasing intensity of footshock punishment and its stability with repeated measurement. This experiment involved a total of 6 rats that were previously trained to selfadminister cocaine during 35 3-h daily sessions. Responsiveness to punishment was defined operationally as the current intensity that suppressed cocaine self-administration by $50 \%$ (i.e., IS50\%). To this end, cocaine self-administration was punished with ascending footshock intensities from 0.1 to $0.9 \mathrm{~mA}$, with an incremental step of $0.2 \mathrm{~mA}$, until complete suppression of behavior. Each measurement session lasted $3.5 \mathrm{~h}$ and was decomposed into 7 successive 30 -min intervals. As explained before, no punishment was administered during the first two 30-min intervals of cocaine self-administration (i.e., 1st hour). The following 530 min intervals of cocaine self-administration were each associated with a footshock punishment of increasing intensity (cf. Figure 1A). To assess stability, responsiveness to punishment was measured two times. Importantly, between measurements, rats were retested for cocaine self-administration without punishment during several days until full recovery to baseline levels of cocaine self-administration (re-baselining). This was done to extinguish any conditioned fear to the context. 
The main result of experiment 1 showed that individual responsiveness to punishment increased considerably between measurements. Strikingly, as a result, in all rats, cocaine use became responsive to the lowest current intensity available that was initially behaviorally ineffective (i.e., $0.1 \mathrm{~mA}$ ) (see Results). The following additional experiments were conducted to further characterize this increased responsiveness to footshock punishment.

Experiment 2: Effects of prior exposure to $0.7-\mathrm{mA}$ footshock punishment on subsequent responsiveness to 0.1-mA footshock punishment

This experiment sought to test the effects of exposure to $0.7-\mathrm{mA}$ footshock on subsequent responsiveness to an initially ineffective footshock intensity (i.e., $0.1 \mathrm{~mA}$ ). $0.7 \mathrm{~mA}$ was shown to suppress completely or near completely cocaine self-administration in rats from experiment 1. Experiment 2 was done in a separate group of rats $(n=6)$ that were previously trained to self-administer cocaine during 27 2.7-h daily sessions. All daily punishment sessions lasted $4 \mathrm{~h}$, with no footshock during the first hour (Figure 1B). Rats were first exposed for one session to $0.1 \mathrm{~mA}$. In experiment 1 , this low intensity did not initially suppress cocaine self-administration in footshock-naïve rats. The day after, they were exposed for one session to $0.7 \mathrm{~mA}$. After exposure to $0.7 \mathrm{~mA}$, rats were retested for cocaine self-administration without punishment (i.e., re-baselining) until full recovery to pre-shock levels of drug intake. Then, they were re-exposed to 0.1-mA footshock once a week during 5 consecutive weeks, each re-exposure occurring after every 4 sessions of re-baselining without punishment. 
Experiment 3: Effects of non-contingent exposure to 0.7-mA footshock on subsequent responsiveness to 0.1-mA footshock punishment

This experiment involved a separate group of rats $(n=12)$ that were previously trained to self-administer cocaine during 332.5 -h sessions. Its design was identical to that of experiment 2, except that $0.7-\mathrm{mA}$ footshock was administered non-contingently without access to cocaine self-administration. Specifically, rats received 7 non-contingent $0.7-\mathrm{mA}$ footshock with variable inter-shock intervals (15-30 min) during a 4-h session. This was done in an attempt to mimic the pattern and number of response-contingent 0.7-mA footshock received by the most exposed rats from experiments 2 and 3. After several re-baselining sessions, rats were re-exposed to 0.1-mA footshock punishment during one session.

Experiment 4: Recovery of initial responsiveness to punishment

This experiment involved a separate group of rats $(n=7)$ that were previously trained to selfadminister cocaine during 22 4-h sessions. Its design was identical to that of experiment 2, except that rats were re-exposed to $0.1-\mathrm{mA}$ footshock punishment during 5 consecutive daily sessions, with no intermediate re-baselining sessions. By reducing the time interval between testing sessions, this procedure was expected to promote recovery of initial responsiveness to footshock punishment. Recovery from response suppression after continuous exposure to the same punishment is a well-established phenomenon that occurs particularly when the intensity of punishment is relatively weak and that is thought to reflect habituation [42]. 
Experiment 5: Generalization to a different, non-painful punishment

This experiment involved a separate group of rats $(n=7)$ that were previously trained to selfadminister cocaine during 19 3-h sessions. Its goal was to test whether the increased responsiveness to punishment seen in previous experiments could generalize to a different type of punishment, histamine. Histamine was shown to serve as an effective punisher of operant behavior reinforced by nondrug and drug rewards [43-50]. All daily histamine punishment sessions lasted $4 \mathrm{~h}$, with no punishment during the first hour. During the last $3 \mathrm{~h}$, cocaine self-administration was punished by co-administering histamine with cocaine upon completion of each FR3 requirement. This procedure required two syringes: one syringe containing cocaine alone and one syringe containing histamine and cocaine, the former being quickly replaced by the latter toward the end of the first hour (i.e., at 59 min for each rat). This was done manually in a manner to avoid introducing air in the i.v. infusion system. In addition, after switching syringes, the syringe pump was briefly activated to flush the volume of solution of pure cocaine remaining in the infusion line (i.e., about 0.6 of the volume of a unit dose) to ensure that the first self-injection will contain the solution of cocaine and histamine. On the first session of punishment, rats received a low dose of histamine (i.e., 0.5 $\mathrm{mg}$ ) with each dose of cocaine. On the following session, they received a much higher dose of histamine (i.e., $6 \mathrm{mg}$ ) with each dose of cocaine. These doses of histamine were selected from a pilot study. After exposure to the 6-mg dose of histamine, rats were re-tested for cocaine self-administration without histamine punishment (i.e., re-baselining) until full recovery of drug intake. Then, they were re-exposed to the $0.5-\mathrm{mg}$ dose of histamine during one session. 
Change in punishment responsiveness

\section{Results}

Experiment 1: Measurement of responsiveness to footshock punishment

Rats $(n=6)$ were first trained to self-administer cocaine during 35 3-h daily sessions until stabilization of drug intake. In total, they obtained $1127.5 \pm 168.0$ unit doses, amounting to an intake of $281.9 \pm 42.0 \mathrm{mg}$. During the last 3 baseline $(\mathrm{BL})$ sessions preceding punishment testing, their within-session rate of self-administration was stable during the last 6 30-min intervals at around 5 cocaine injections every 30 min (Figure 2A). The first 30-min interval of each session was systematically ignored because it includes initial drug loading (see Data Analysis). In contrast, during the first session of footshock punishment (footshock 1), there was a current intensity-dependent suppression of cocaine self-administration compared to baseline $(F 5,25=27.65, p<0.01)$ (Figure $2 A)$. There was initially no suppression of cocaine self-administration at $0.1 \mathrm{~mA}$ (the lowest current intensity tested), an intermediate level of suppression at $0.3 \mathrm{~mA}$ (Tukey HSD, $\mathrm{p}<0.01$ ) and, finally, a near complete suppression above $0.5 \mathrm{~mA}$ (Tukey HSD, p<0.01). The mean current intensity that inhibits or suppresses the rate of cocaine self-administration by $50 \%$ (or IS50\%; see Data Analysis) was estimated to be $0.24 \pm 0.02 \mathrm{~mA}$ (Figure 2B). Importantly, when rats were re-tested for footshock punishment (footshock 2) after several sessions of re-baselining, responsiveness to footshock punishment increased, as indicated by a large leftward shift of the intensity-suppression curve compared to footshock1 $(F 5,25=14.99, p<0.01)$ (Figure $2 A)$ and a lowering of the IS50\% (F1,5=21.43, $\mathrm{p}<0.01)$ (Figure 2B). As a result, all rats suppressed their cocaine selfadministration at $0.1 \mathrm{~mA}$, the lowest and initially ineffective footshock intensity tested and which was initially behaviorally ineffective (Figure 2 B). 
Interestingly, during re-baselining after the first footshock punishment session, there was some evidence for protracted suppression of cocaine self-administration (Figure 2C), probably a carryover from punishing training. However, this effect was modest $(F 6,30=2.59$, $\mathrm{p}<0.05)$ and short-lived, as full recovery to initial levels of cocaine self-administration was observed as early as the second re-baselining session onward.

Experiment 2: Effects of prior exposure to $0.7-\mathrm{mA}$ footshock punishment on subsequent responsiveness to $0.1-\mathrm{mA}$ footshock punishment

This experiment involved a separate group of 6 rats that were first trained to self-administer cocaine during 27 2.7-h daily sessions until stabilization of behavior. In total, they obtained $716.0 \pm 78.0$ unit doses, amounting to an intake of $179.0 \pm 19.5 \mathrm{mg}$. During the last 3 baseline sessions preceding punishment testing, their within-session rate of selfadministration was stable at around 5 cocaine injections every 30 min (Figure 3A, black circles), as rats from experiment 1 . Then, rats were subjected on different sessions to different intensities of footshock punishment (i.e., 0.1 and $0.7 \mathrm{~mA}$ ) (see Methods). As expected, rats did not change their intake of cocaine when their behavior was punished with $0.1 \mathrm{~mA}(\mathrm{~F} 6,30=1.01, \mathrm{~ns})$ (Figure 3A, open circles). In contrast, the day after, they almost completely stopped self-administering cocaine when the current intensity of footshock punishment was increased to $0.7 \mathrm{~mA}(F 6,30=7.90, p<0.01)$ (Figure $3 \mathrm{~A})$. The latter effect was relatively rapid since it began to occur during the first 30-min of punishment (i.e., $2^{\text {nd }}$ interval in Figure $3 \mathrm{~A}$ ). When rats were re-tested with $0.1 \mathrm{~mA}$ after pre-exposure to $0.7 \mathrm{~mA}$ and rebaselining, they stopped taking cocaine almost completely, showing a dramatic increase in responsiveness to footshock punishment $(F 6,30=3.20, p<0.01)$ (Figure 3B). Average rate of cocaine injections per 30 min over the 3-h period of punishment dropped in all individual rats tested (Figure 3B, right panel). Though there were some fluctuations, this increased 
Change in punishment responsiveness

responsiveness to $0.1 \mathrm{~mA}$ tended to persist with repeated testing between re-baselining sessions and lasted during at least one month (Punishment: F1,5=921.00, $p<0.01$;

Punishment $\times$ Session: F4,20=0.86, ns) (Figure 3C).

Experiment 3: Effects of non-contingent exposure to 0.7-mA footshock on subsequent responsiveness to 0.1-mA footshock punishment

A separate group of 12 rats was used in this experiment. They were first trained to selfadminister cocaine during 332.5 -h daily sessions until stabilization of drug intake. In total, they obtained $895.7 \pm 96.2$ unit doses, amounting to an intake of $223.9 \pm 24.0 \mathrm{mg}$ of cocaine. During the last 3 baseline sessions preceding punishment testing, their within-session rate of self-administration was stable at around 5 injections every 30 min. Rats initially decreased slightly, but significantly, their intake of cocaine when their behavior was punished with 0.1mA footshock punishment (Session $x$ Interval: F6,66=2.56, $p<0.05$ ). However, in sharp contrast with previous experiments, after one session of non-contingent exposure to $0.7 \mathrm{~mA}$ in absence of cocaine self-administration, there was no change in responsiveness of drug use to $0.1 \mathrm{~mA}$ (Session $x$ Interval: F6,66=1.77, ns) (Figure 3D). Similar results were obtained when the analysis was confined to the subgroup of rats $(n=7)$ whose drug use behavior was initially not responsive to $0.1 \mathrm{~mA}$ (Session $\mathrm{x}$ Interval: $\mathrm{F} 6,36=1.16$, ns).

Experiment 4: Recovery of initial responsiveness to punishment

This experiment involved a separate group of 7 rats that were first trained to self-administer cocaine during 22 4-h daily sessions until stabilization of drug intake. In total, they obtained $928.1 \pm 107.9$ unit doses, amounting to an intake of $232.0 \pm 27.0 \mathrm{mg}$ of cocaine. During the 
last 3 baseline sessions, their within-session rate of cocaine self-administration was stable at around 6 injections every 30 min (Figure 4A). As in experiment 2, rats did not initially change their intake of cocaine when their behavior was punished with $0.1 \mathrm{~mA}$, except during the $1^{\text {st }}$ 30 min of exposure $(F 6,36=3.31, p<0.05)$, but increased their responsiveness to this intensity after having experienced one punishment session with $0.7 \mathrm{~mA}(F 6,36=3.06, \mathrm{p}<0.01)$ (Figure 4B) during which they nearly completely stopped to self-administer cocaine $(F 6,36=47.54$, $p<0.01$ ) (Figure 4A). Once again, average rate of cocaine injections per 30 min over the 3-h period of punishment dropped in all individual rats tested (Figure 4B, right panel). Interestingly, however, when rats were tested repeatedly with $0.1 \mathrm{~mA}$ during multiple consecutive sessions that were not spaced by intermediate re-baselining sessions, they rapidly recovered their initial responsiveness to $0.1 \mathrm{~mA}$, suggesting a habituation-like effect $(F 4,24=2.30, p=0.08)$ (Figure 4C).

Experiment 5: Generalization to a different, non-painful punishment This experiment was conducted on a separate group of 7 rats. They were first trained to selfadminister cocaine during 19 3-h daily sessions until stabilization of drug intake. In total, they obtained $432.4 \pm 76.2$ unit doses, amounting to an intake of $108.1 \pm 19.1 \mathrm{mg}$ of cocaine. During the last 3 baseline sessions preceding punishment testing, their within-session rate of self-administration was stable at around 4 injections every 30 min (Figure 5A). As expected, rats did not suppress their cocaine self-administration behavior at the lowest dose of histamine $(0.5 \mathrm{mg} / \mathrm{injection})(\mathrm{F} 6,36=0.67, \mathrm{~ns})$ but reduced considerably their intake of cocaine when their behavior was punished with the highest dose (6 mg/injection) $(F 6,36=2.23, p=0.06)$ (Figure $5 A)$. The latter punishing effect was comparable in time-course and magnitude to that seen with $0.7 \mathrm{~mA}$ of footshock punishment in experiments 2 and 3 . However, when rats were re-tested with the lowest dose of histamine after pre-exposure to 


\section{Change in punishment responsiveness}

the highest dose and re-baselining, their behavior remained as unresponsive to this dose as initially $(F 6,36=0.67, \mathrm{~ns})$ (Figure 5B). 
Change in punishment responsiveness

\section{Discussion}

Overall, the present study shows that responsiveness of cocaine self-administration to footshock punishment can change considerably with repeated testing. Notably, we found that increased responsiveness to punishment was mainly due to prior experience with an intensity of footshock punishment that near completely suppressed drug self-administration (i.e., $0.7 \mathrm{~mA}$ ). After this experience, rats suppressed their cocaine intake when their behavior was punished with a low and initially largely ineffective footshock intensity (i.e., $0.1 \mathrm{~mA}$ ). This increased responsiveness to punishment was manifest after only few response-footshock punishment pairings, but not after the same number of passive exposure to footshock in the self-administration context. It occurred when the 0.1-mA and 0.7-mA intensities of footshock punishment were experienced in separate sessions and after post-punishment recovery to baseline levels of cocaine self-administration. Once acquired, the persistence of this increased responsiveness to punishment mainly depended on how often cocaine selfadministering rats subsequently re-experienced 0.1-mA footshock punishment. Increased responsiveness to punishment returned to normal within 2-3 days when the same 0.1-mA punishment was re-experienced every day but could persist during at least one month when it was re-experienced more intermittently every other week. Recovery of initial responsiveness to punishment seen after repeated daily testing probably reflects a habituation-like process [42]. In the present series of experiments, increased responsiveness of cocaine use to footshock punishment was observed in all individual rats, albeit with varying degrees, after experience with more intense footshock punishment. Finally, increased responsiveness to punishment was not observed with a non-painful form of punishment (i.e., pharmacological punishment with histamine) that is also sometimes used to punish drug self-administration in animal studies $[44,45,47,50]$. The reason for this lack of 
Change in punishment responsiveness

generalizability across different types of punishers is not clear at present and may suggest that this phenomenon may be specific to painful punishment.

\section{Possible underlying mechanisms for change in responsiveness to punishment}

The associative process underlying increased responsiveness of cocaine use to footshock punishment remains to be fully explored $[15,42]$. Nevertheless, our findings allow us to begin to narrow down some of the possible interpretations. In experiment 1, since 0.1-mA footshock was experienced before higher intensities in the same session, one could hypothesize that mild footshock has become a cue that more intense footshock will occur later in the session. However, this within-session predictive relationship fails to explain the same findings obtained in experiments 2 and 4 in which 0.1-mA and 0.7-mA were experienced in two separate daily sessions. According to another possibility that can account for the findings of experiments 1,2 and 4, 0.1-mA footshock would function as a cue that 0.7$\mathrm{mA}$ footshock can occur in the current context, thereby reinstating Pavlovian fear to the context which, in turn, would cause suppression of operant responding [42]. This possibility is unlikely, however, since no change in responsiveness to punishment was seen after noncontingent exposure to 0.7-mA footshock, despite equal footshock-context pairings. The latter finding also rules out the possible role of a pain sensitization process. Finally, another, perhaps more likely possibility would be that 0.1-mA footshock somehow comes to function as a cue that operant responding for cocaine can be punished by $0.7-\mathrm{mA}$ footshock. The latter explanation presupposes that rats have previously learned the contingency between operant responding and punishment. Though this was not formally demonstrated here using ideal control procedures [15], such learning is likely predominant in driving suppression of drug use in our punishment procedure. Previous research showed that such contingency can be learned rapidly using punishment schedule conditions similar to those used in the present 
experiments [51]. For instance, in an experiment involving two distinct operant responses, one punished by footshock, the other unpunished, rats rapidly stopped making the punished response but not the unpunished one (i.e., within the first 20 min of the first punishment session) [51]. However, future research using procedures that directly control for responsepunishment contingency should help to better understand the mechanisms underlying the increased responsiveness of cocaine use to punishment reported here.

Of particular note, in the present series of experiments, footshock was systematically delivered with cocaine following each operant response requirement (see Methods for additional information). It may be argued that this footshock-cocaine pairing could weaken the punishing effects of footshock via a counterconditioning mechanism [15]. However, our data are clearly not consistent with this possibility.

The phenomenon of increased responsiveness to footshock punishment is not entirely new. It has been previously reported, though not discussed explicitly, in studies in which rats were re-tested with footshock punishment after prior experience with intensities of footshock punishment that near-completely suppressed drug self-administration $[35,36]$. Specifically, in those studies, rats were tested twice with increasing intensity of footshock punishment until they showed a complete suppression of cocaine self-administration. As demonstrated here, during the second test, rats suppressed their cocaine intake when their behavior was punished with footshock intensities lower than during the first test. Importantly, in these studies, the intensity of footshock punishment was increased between-session, not withinsession as in the present study, reinforcing the generality of the observed phenomenon. It is also interesting to note that studies that failed to observe increased responsiveness to footshock punishment tested rats with a relatively narrow range of intensity that only partially 
suppressed drug self-administration $[28,37,38]$. Thus, it seems that what matters most is prior experience with an intensity of footshock punishment that is sufficient to nearcompletely suppress drug self-administration, as shown here. However, this factor, though necessary, does not seem to be sufficient. In some studies, a range of footshock intensity that completely suppressed responding for a nondrug reward did not lead to an increased responsiveness to footshock punishment during retesting $[37,38]$. In addition, the way the intensity of footshock punishment is increased also matters a lot. For instance, when this intensity is slowly and gradually increased across many days (and not increased rapidly as in the present study), responding by rats becomes less, not more, responsive to footshock punishment $[52,53]$. Thus, it seems that acquisition of increased responsiveness of cocaine self-administration to footshock punishment depends on an interaction between several environmental factors. Future studies are needed to fully explore this interaction and also to determine whether it is generalizable to other addictive drugs.

Relevance and future perspectives for research on animal models of addiction

The present study has implications for the interpretation of continued drug self-administration despite punishment as a model of compulsion-like behavior. As explained in the Introduction, previous parametric studies, including the present study, have revealed that responsiveness of drug self-administration to footshock punishment is intensity-dependent. When a sufficiently broad range of footshock intensities is used, each individual animal eventually experiences a current intensity that leads it to stop self-administering the drug $[26,29,33,35,36]$. What differs between individuals is not their ability to stop drug use per se, but the specific intensity of punishment that causes them to stop drug use. Some individuals stop drug use at higher intensities of footshock punishment than other individuals. Here we show that initial responsiveness of drug use to footshock punishment can dramatically 
change with experience, thereby further exposing the ability of rats to control drug use. In the present series of experiments, this change in responsiveness to punishment was observed, with varying degrees, in all individual rats tested. Thus, lack of initial responsiveness of drug use to punishment, especially when the same weak intensity is used, should be interpreted with caution as evidence for loss of control or compulsion-like behavior in animals. Several other factors may also explain why under certain conditions, individuals continue using drugs despite punishment, including a difficulty to learn response-punishment contingencies $[54,55]$. It remains to be seen whether the prevalence of individuals with increased responsiveness to punishment reported in the present study could change after longeraccess conditions to cocaine or opioid for self-administration, and also as a function of some important organismic factors, such as, for instance, sex, age and strain.

The present study identified punishment intensity has an important factor which can dramatically increase responsiveness of drug use to punishment. It will be important to know in future research what other factors can also contribute to change responsiveness to punishment, preferably in a persistent manner. Of particular interest, it remains to be seen whether future parametric studies could eventually stumble on a set of punishment parameters that suppresses drug use persistently without recovery [42]. This research could be particularly relevant to better understand why some individuals eventually quit drugs, notably after hitting rock bottom or after having experienced a particularly intense negative event [8]. Inversely, it will be interesting to investigate in future research the specific conditions that favor a decreased responsiveness to punishment, as when responding is punished by slow and gradual increase in punishment intensity over many days $[52,53]$. If the negative consequences of drug use accumulate slowly and gradually over time, such conditions may contribute to explain, at least partly, why some individuals continue using despite these negative consequences, without postulating a state of compulsion or loss of 
Change in punishment responsiveness

control whose intelligibility is questionable $[6,7]$ and whose existence is not well supported by recent human neuroimaging research [54-57]. 


\section{Acknowledgements}

We thank Christophe Bernard, Mathieu Louvet and Eric Wattelet for administrative assistance. We also thank Drs. Karine Guillem and Magalie Lenoir for their helpful comments on a previous version of the manuscript. We also thank Pr. Gavan McNally for bringing our attention to the old literature on punishment. We also thank the reviewers for their insightful and constructive criticisms.

\section{Funding and Disclosure}

The authors declare that they have no conflict of interest. This work was supported by the French Research Council (CNRS), the Université de Bordeaux, the Conseil Régional d'Aquitaine (CRA20101301022; CRA11004375/11004699) and the French National Agency (ANR2010-BLAN-1404-01, ANR-10-EQX-008-1, LabEx BRAIN). LF was supported by the CAPES-Brazilian Federal Agency for Support and Evaluation of Graduate Education within the Ministry of Education of Brazil.

\section{Author contribution}

SHA conceived the project. AD, SHA designed the experiments. AD carried out the experiments with the participation of $P G$ and $L F$. AD collected the experimental data. AD, SHA analyzed the data. AD, SHA wrote the paper. All authors reviewed content and approved the final version of the manuscript. 


\section{Figure legends}

Figure 1: Experimental designs and procedures. (A) Measurement of responsiveness to footshock punishment in experiment 1 . The first box represents baseline sessions with no footshock punishment of cocaine self-administration. The second box corresponds to footshock punishment sessions. These sessions were subdivided into 7 30-min periods, corresponding each to a different current intensity: 0 to $0.9 \mathrm{~mA}$. (B) Procedure for experiments 2 and 3 . The first box represents baseline sessions with no punishment. The second and third boxes represent punishment sessions with 0.1 and $0.7 \mathrm{~mA}$, respectively. Note that no punishment was delivered during the first 2 30-min intervals of footshock sessions.

Figure 2: Measurement of responsiveness to footshock punishment. (A) Footshock punishment-induced suppression of cocaine self-administration $(n=6)$. Number of cocaine injections (mean \pm s.e.m.) during baseline or footshock punishment sessions (footshock 1 and 2) as a function of increasing current intensity. ${ }^{* \star} p<0.01$, different from baseline; \# p<0.01, different from footshock 1. (B) Current intensity (mean \pm s.e.m.) that suppresses by $50 \%$ (IS50\%) the rate of cocaine self-administration. Lowering of IS50\% during repeated exposure to footshock punishment. ${ }^{\star *}$, different from footshock $1(p<0.01)$. Each individual is represented by two grey circles linked with a solid line. Darker grey indicates overlapping individuals. (C) Progressive recovery to baseline levels of cocaine self-administration (mean \pm s.e.m.) during intermediate re-baselining sessions. ${ }^{\star}$, different from last baseline session before footshock $1(p<0.01)$. 


\section{Figure 3: Persistent increase in responsiveness to footshock punishment after} experience with 0.7-mA footshock punishment. (A) Number of cocaine injections (mean \pm s.e.m.) during baseline sessions or footshock sessions with current intensity set to 0.1 or 0.7 $m A(n=6)$. The horizontal grey box indicates when cocaine self-administration was punished by footshock during footshock sessions. Note that no punishment was delivered during the first 30-min interval. ${ }^{* *} p<0.01$, different from baseline. (B) Effects of punishment with $0.1 \mathrm{~mA}$ on number of cocaine injections (mean \pm s.e.m.) before and after exposure to one session with 0.7-mA footshock punishment. ${ }^{* *} \mathrm{p}<0.01$, different from Pre $0.7 \mathrm{~mA}$. Right panel: Average rate of cocaine injections per 30 min over the last $3 \mathrm{~h}$ of punishment for all individual rats, each represented by two grey circles linked with a solid line. Darker grey indicates overlapping individuals. (C) Persistent increase in responsiveness to footshock punishment over time. Number of cocaine injections (mean \pm s.e.m.) during punishment with $0.1 \mathrm{~mA}$ (i.e., last 6 30-min intervals) remained below control levels (i.e., $0.0 \mathrm{~mA}$ corresponding to the 30 min interval preceding onset of punishment) during repeated testing sessions. Testing sessions were interspersed by 4 intermediate re-baselining sessions. ${ }^{\star \star} p<0.01$, different from $0.0 \mathrm{~mA}$. (D) Effects of punishment with $0.1 \mathrm{~mA}$ on number of cocaine injections (mean \pm s.e.m.) before and after exposure to one session with non-contingent 0.7-mA footshock $(n=$ 12). Right panel: Average rate of cocaine injections per 30 min over the last $3 \mathrm{~h}$ of punishment for all individual rats, each represented by two grey circles linked with a solid line. Darker grey indicates overlapping individuals.

Figure 4: Recovery of initial responsiveness to footshock punishment. (A) Number of cocaine injections (mean \pm s.e.m.) during baseline sessions or footshock sessions with current intensity set to 0.1 or $0.7 \mathrm{~mA}(n=7) .{ }^{*} p<0.05,{ }^{* \star} p<0.01$, different from baseline. (B) Effects of 0.1-mA footshock punishment on number of cocaine injections (mean \pm s.e.m.) before and after exposure to 0.7-mA footshock punishment. * $p<0.05,{ }^{* \star} p<0.01$, different 
from before exposure to $0.7 \mathrm{~mA}$. Right panel: Average rate of cocaine injections per $30 \mathrm{~min}$ over the last $3 \mathrm{~h}$ of punishment for all individual rats, each represented by two grey circles linked with a solid line. Darker grey indicates overlapping individuals. (C) Recovery of initial responsiveness to footshock punishment. Number of cocaine injections (mean \pm s.e.m.) during punishment with $0.1 \mathrm{~mA}$ (i.e., last 6 30-min intervals) compared to control levels (i.e., $0.0 \mathrm{~mA}$ corresponding to the 30 -min interval preceding onset of punishment) during repeated testing with no intermediate re-baselining sessions. ${ }^{* \star} p<0.01$, different from $0.0 \mathrm{~mA}$. For additional information, see legend of Figure 3.

Figure 5: No change in responsiveness to histamine punishment. (A) Number of cocaine injections (mean \pm s.e.m.) during baseline sessions or during sessions punished with 0.5 or $6 \mathrm{mg}$ of i.v. histamine $(n=7)$. The horizontal grey box indicates when cocaine selfadministration was punished by histamine during corresponding punishment sessions. Note that no punishment was delivered during the first 30 -min interval. * $p<0.05,{ }^{* *} p<0.01$, different from baseline. (B) Effects of 0.5-mg histamine punishment on number of cocaine injections (mean \pm s.e.m.) before and after exposure to one session with 6-mg histamine punishment. Right panel: Average rate of cocaine injections per 30 min over the last $3 \mathrm{~h}$ of punishment for all individual rats, each represented by two grey circles linked with a solid line. Darker grey indicates overlapping individuals. 


\section{References}

1 Association AP. Diagnostic and statistical manual of mental disorders (DSM-5). American Psychiatric Association: Washington, DC; 2013.

2 Martin CS, Langenbucher JW, Chung T, Sher KJ. Truth or consequences in the diagnosis of substance use disorders. Addiction. 2014;109(11):1773-8.

3 Hasin DS, O'Brien CP, Auriacombe M, Borges G, Bucholz K, Budney A, et al. DSM-5 criteria for substance use disorders: recommendations and rationale. Am J Psychiatry. 2013;170(8):83451.

4 Pickard $\mathrm{H}$, Ahmed $\mathrm{SH}$. How do you know you have a drug problem? The role of knowledge of negative consequences in explaining drug choice in humans and rats. In: Heather N, Segal G, editors. Addiction and choice. Oxford: Oxford University Press; 2017. p. 29-48.

$5 \quad$ Klingemann $\mathrm{H}$, Sobell MB, Sobell LC. Continuities and changes in self-change research. Addiction. 2010;105(9):1510-8.

6 Heather N. Is the concept of compulsion useful in the explanation or description of addictive behaviour and experience? Addictive Behaviors Reports. 2017;6:15-38.

7 Hogarth L. Addiction is driven by excessive goal-directed drug choice under negative affect: translational critique of habit and compulsion theory. Neuropsychopharmacology. 2020;45(5):720-35.

8 Heyman GM. Quitting drugs: quantitative and qualitative features. Annu Rev Clin Psychol. 2013;9:29-59.

9 Smith GS, Davis, M. Punishment of amphetamine and morphine self-administration behavior. The psychological record. 1974;24:477-80.

10 Grove RN, Schuster CR. Suppression of cocaine self-administration by extinction and punishment. Pharmacol Biochem Behav. 1974;2(2):199-208.

11 Bergman J, Johanson CE. The effects of electric shock on responding maintained by cocaine in rhesus monkeys. Pharmacol Biochem Behav. 1981;14(3):423-6.

12 Wolffgramm J, Heyne A. From controlled drug intake to loss of control: the irreversible development of drug addiction in the rat. Behav Brain Res. 1995;70(1):77-94.

13 Vanderschuren LJMJ, Minnaard AM, Smeets JAS, Lesscher HM. Punishment models of addictive behavior. Current Opinion in Behavioral Sciences. 2017;13:77-84.

14 Vanderschuren L, Ahmed SH. Animal Models of the Behavioral Symptoms of Substance Use Disorders. Cold Spring Harbor perspectives in medicine. 2020.

15 Jean-Richard-Dit-Bressel P, Killcross S, McNally GP. Behavioral and neurobiological mechanisms of punishment: implications for psychiatric disorders.

Neuropsychopharmacology. 2018;43(8):1639-50.

16 Ahmed SH. "A walk on the wild side" of addiction: the history and significance of animal models. In: Pickard H, Ahmed SH, editors. The Routledge Handbook of Philosophy and Science of Addiction. New York: Routledge; 2019. p. 192-204.

17 Ahmed SH. In search of addiction in the brains of laboratory animals. Evaluating the Brain Disease Model of Addiction. Routledge; in press.

18 Deroche-Gamonet V, Belin D, Piazza PV. Evidence for addiction-like behavior in the rat. Science. 2004;305(5686):1014-7.

19 Panlilio LV, Thorndike EB, Schindler CW. Reinstatement of punishment-suppressed opioid self-administration in rats: an alternative model of relapse to drug abuse.

Psychopharmacology (Berl). 2003;168(1-2):229-35.

20 Chen BT, Yau HJ, Hatch C, Kusumoto-Yoshida I, Cho SL, Hopf FW, et al. Rescuing cocaineinduced prefrontal cortex hypoactivity prevents compulsive cocaine seeking. Nature. 2013;496(7445):359-62. 
21 Pascoli V, Terrier J, Hiver A, Luscher C. Sufficiency of Mesolimbic Dopamine Neuron Stimulation for the Progression to Addiction. Neuron. 2015;88(5):1054-66.

22 Ahmed SH. Validation crisis in animal models of drug addiction: beyond non-disordered drug use toward drug addiction. Neurosci Biobehav Rev. 2010;35(2):172-84.

23 Ahmed SH. The science of making drug-addicted animals. Neuroscience. 2012;211:107-25.

24 Kasanetz F, Deroche-Gamonet V, Berson N, Balado E, Lafourcade M, Manzoni O, et al. Transition to addiction is associated with a persistent impairment in synaptic plasticity. Science. 2010;328(5986):1709-12.

25 Kasanetz F, Lafourcade M, Deroche-Gamonet V, Revest JM, Berson N, Balado E, et al. Prefrontal synaptic markers of cocaine addiction-like behavior in rats. Mol Psychiatry. 2013;18(6):729-37.

26 Farrell MR, Ruiz CM, Castillo E, Faget L, Khanbijian C, Liu S, et al. Ventral pallidum is essential for cocaine relapse after voluntary abstinence in rats. Neuropsychopharmacology. 2019;44(13):2174-85.

27 Giuliano C, Belin D, Everitt BJ. Compulsive Alcohol Seeking Results from a Failure to Disengage Dorsolateral Striatal Control over Behavior. J Neurosci. 2019;39(9):1744-54. Giuliano C, Pena-Oliver Y, Goodlett CR, Cardinal RN, Robbins TW, Bullmore ET, et al. Evidence for a Long-Lasting Compulsive Alcohol Seeking Phenotype in Rats. Neuropsychopharmacology. 2018;43(4):728-38. Krasnova IN, Marchant NJ, Ladenheim B, McCoy MT, Panlilio LV, Bossert JM, et al. Incubation of methamphetamine and palatable food craving after punishment-induced abstinence. Neuropsychopharmacology. 2014;39(8):2008-16. Torres OV, Jayanthi S, Ladenheim B, McCoy MT, Krasnova IN, Cadet JL. Compulsive methamphetamine taking under punishment is associated with greater cue-induced drug seeking in rats. Behav Brain Res. 2017;326:265-71.

31 Marchant NJ, Campbell EJ, Whitaker LR, Harvey BK, Kaganovsky K, Adhikary S, et al. Role of Ventral Subiculum in Context-Induced Relapse to Alcohol Seeking after Punishment-Imposed Abstinence. J Neurosci. 2016;36(11):3281-94.

32 Marchant NJ, Kaganovsky K, Shaham Y, Bossert JM. Role of corticostriatal circuits in contextinduced reinstatement of drug seeking. Brain Res. 2015;1628(Pt A):219-32.

33 Marchant NJ, Khuc TN, Pickens CL, Bonci A, Shaham Y. Context-induced relapse to alcohol seeking after punishment in a rat model. Biol Psychiatry. 2013;73(3):256-62.

34 Marchant NJ, Rabei R, Kaganovsky K, Caprioli D, Bossert JM, Bonci A, et al. A critical role of lateral hypothalamus in context-induced relapse to alcohol seeking after punishmentimposed abstinence. J Neurosci. 2014;34(22):7447-57.

35 Pelloux Y, Hoots JK, Cifani C, Adhikary S, Martin J, Minier-Toribio A, et al. Context-induced relapse to cocaine seeking after punishment-imposed abstinence is associated with activation of cortical and subcortical brain regions. Addict Biol. 2018;23(2):699-712.

36 Pelloux Y, Minier-Toribio A, Hoots JK, Bossert JM, Shaham Y. Opposite Effects of Basolateral Amygdala Inactivation on Context-Induced Relapse to Cocaine Seeking after Extinction versus Punishment. J Neurosci. 2018;38(1):51-59.

37 Datta U, Martini M, Fan M, Sun W. Compulsive sucrose- and cocaine-seeking behaviors in male and female Wistar rats. Psychopharmacology (Berl). 2018;235(8):2395-405.

38 Datta U, Martini M, Sun W. Different functional domains measured by cocaine selfadministration under the progressive-ratio and punishment schedules in male Wistar rats. Psychopharmacology (Berl). 2018;235(3):897-907.

39 Ahmed SH, Koob GF. Transition to drug addiction: a negative reinforcement model based on an allostatic decrease in reward function. Psychopharmacology (Berl). 2005;180(3):473-90. 
40 Pickens R, Meisch RA, Thompson T. Drug self-administration: an analysis of the reinforcing effects of drugs. In: Iversen LL, Iversen, S.D., Solomon, S.H., editor Handbook of Psychopharmacology: Drugs of Abuse. New York: Plenum Press; 1978. p. 1-37.

41 Yokel RA. Intravenous self-administration: response rates, the effects of pharmacological challenges, and drug preference. In: Bozarth MA, editor Methods of Assessing the Reinforcing Properties of Abused Drugs. New York: Springer-Verlag; 1987. p. 1-33.

42 Fontes RM, Shahan TA. Punishment and its putative fallout: A reappraisal. J Exp Anal Behav. 2021;115(1):185-203.

43 Holtz NA, Carroll ME. Cocaine self-administration punished by intravenous histamine in adolescent and adult rats. Behav Pharmacol. 2015;26(4):393-7.

$44 \quad$ Negus SS. Effects of punishment on choice between cocaine and food in rhesus monkeys. Psychopharmacology (Berl). 2005;181(2):244-52.

45 Gancarz-Kausch AM, Adank DN, Dietz DM. Prolonged withdrawal following cocaine selfadministration increases resistance to punishment in a cocaine binge. Scientific reports. 2014;4:6876.

46 Goldberg SR. Histamine as a punisher in squirrel monkeys: effects of pentobarbital, chlordiazepoxide and $\mathrm{H} 1$ - and $\mathrm{H} 2$-receptor antagonists on behavior and cardiovascular responses. J Pharmacol Exp Ther. 1980;214(3):726-36.

47 Holtz NA, Anker JJ, Regier PS, Claxton A, Carroll ME. Cocaine self-administration punished by i.v. histamine in rat models of high and low drug abuse vulnerability: effects of saccharin preference, impulsivity, and sex. Physiol Behav. 2013;122:32-8.

48 Podlesnik CA, Jimenez-Gomez C, Woods JH. A choice procedure to assess the aversive effects of drugs in rodents. J Exp Anal Behav. 2010;93(2):203-23.

49 Woolverton WL. A novel choice method for studying drugs as punishers. Pharmacol Biochem Behav. 2003;76(1):125-31.

50 Woolverton WL, Freeman KB, Myerson J, Green L. Suppression of cocaine self-administration in monkeys: effects of delayed punishment. Psychopharmacology (Berl). 2012;220(3):509-17.

51 Bolles RC, Holtz R, Dunn T, Hill W. Comparisons of stimulus learning and response learning in a punishment situation. Learning and motivation. 1980;11:78-96.

52 Miller NE. Learning resistance to pain and fear: effects of overlearning, exposure, and rewarded expsure in context. Journal of experimental psychology. 1960;60:137-45.

53 Terris $W$, Barnes $M$. Learned resistance to punishment and subsequent responsiveness to the same and novel punishments. Psychon Sci. 1969;15(1):49-50.

54 Kober H, Kross EF, Mischel W, Hart CL, Ochsner KN. Regulation of craving by cognitive strategies in cigarette smokers. Drug Alcohol Depend. 2010;106(1):52-5.

55 Suzuki S, Mell MM, O'Malley SS, Krystal JH, Anticevic A, Kober H. Regulation of Craving and Negative Emotion in Alcohol Use Disorder. Biological psychiatry Cognitive neuroscience and neuroimaging. 2020;5(2):239-50.

56 Volkow ND, Fowler JS, Wang GJ, Telang F, Logan J, Jayne M, et al. Cognitive control of drug craving inhibits brain reward regions in cocaine abusers. Neuroimage. 2010;49(3):2536-43.

57 Parvaz MA, Malaker P, Zilverstand A, Moeller SJ, Alia-Klein N, Goldstein RZ. Attention bias modification in drug addiction: Enhancing control of subsequent habits. Proc Natl Acad Sci U S A. 2021;118(23). 


\section{Figure 1}

\section{A Design for experiment 1}

\begin{tabular}{|c|c|c|c|c|c|c|c|}
\hline \multirow{2}{*}{$\begin{array}{l}\text { Baseline } \\
\text { Footshock }\end{array}$} & \multicolumn{7}{|c|}{ 3.5-h session of cocaine SA } \\
\hline & 0.0 & 0.0 & 0.1 & 0.3 & 0.5 & 0.7 & 0.9 \\
\hline
\end{tabular}

B Design for experiments 2-4

\begin{tabular}{|c|c|c|c|}
\hline Baseline & \multicolumn{3}{|c|}{ 4-h session of cocaine SA } \\
\hline Footshock & 0.0 & 0.0 & $0.1 \mathrm{~mA}$ \\
\hline Footshock & 0.0 & 0.0 & $0.7 \mathrm{~mA}$ \\
\hline
\end{tabular}


Figure 2



\section{Figure 3}


No effect of non-contingent footshock

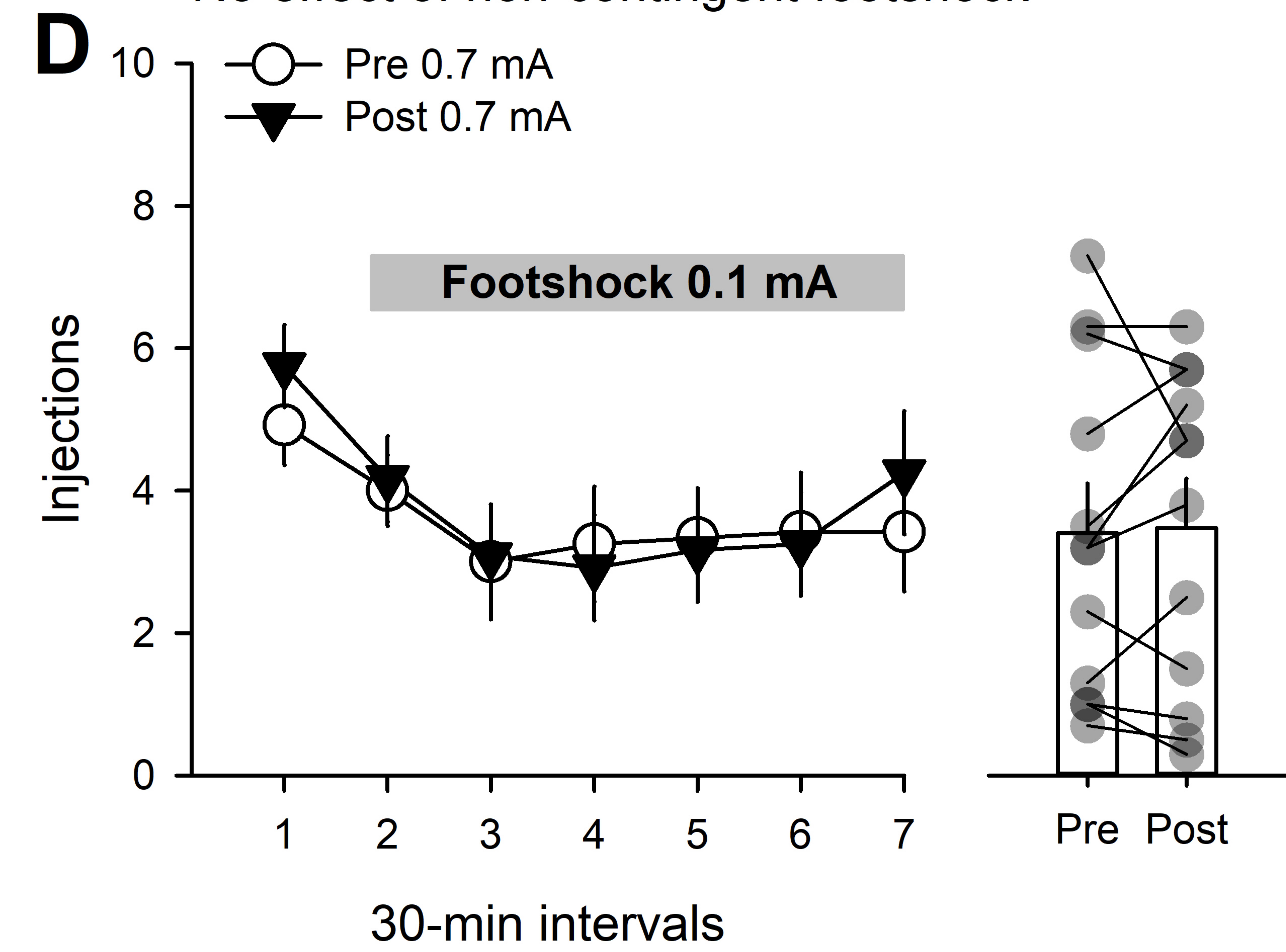




\section{Figure 4}


Daily testing sessions 
Figure 5

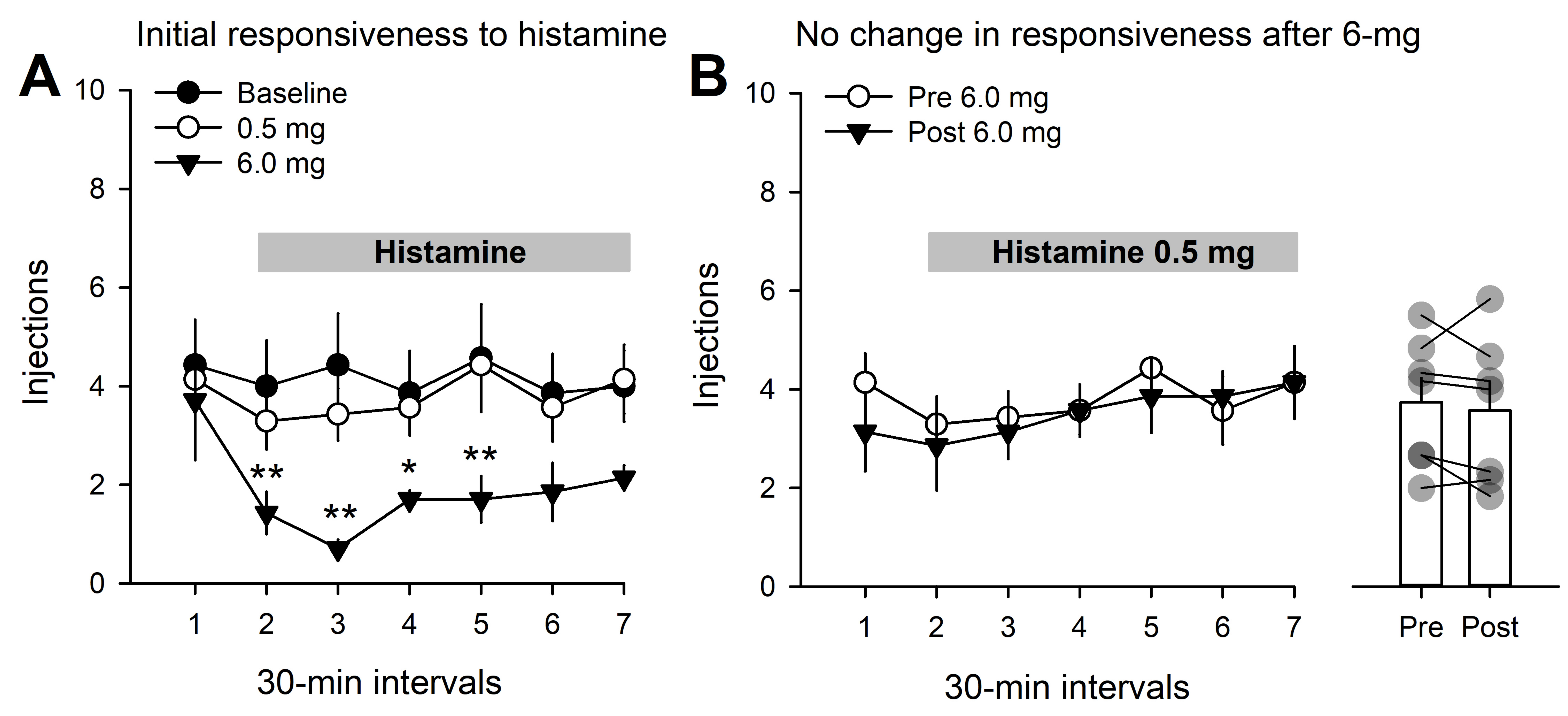

